\title{
Analysis on Patent Situation and Layout in the Field of Water Pollution Control
}

\author{
ZHANG Hui ${ }^{\mathrm{a}}$, HE Zhili ${ }^{*}$ \\ School of Law, Daqing Normal University, Daqing, P.R. China \\ aZhanghui4517@163.com, ${ }^{\text {bnowheremanziyi@163.com }}$
}

Keywords: Water pollution control; Patent; Literature statistics; Trend analysis.

Abstract. In order to clarify the technical layout and development trend of water pollution control research in China, this paper analyzes the related domestic patent application of the water pollution control from 1985 to the present based on the Soopat patent search database, and analyzes the time layout of the patent, the cooperation among applicants, the layout in the field of water pollution control, the technical layout IPC classification, and the patent legal status analysis, etc. This paper tries to reveal the overall domestic patent development trend and layout in this field, and provide information reference for China's water pollution control field development strategy.

\section{Introduction}

With the continual increase of the water pollution hazards to the ecological environment, industrial production, daily life and human health, the seriousness of water pollution has attracted worldwide attention. In order to promote the coordinated development of economy and water resources, it is very important to establish and develop water pollution control industry. The development of water pollution control industry can not only achieve the source control and whole process control of water environment problem, and cultivate new economic growth point, but also can speed up industrial restructuring, and obtain industrial sustainable development [1,2].

A patent is an exclusive right granted for an invention [3]. The patent literature contains $90 \%$ $-95 \%$ of the world's scientific and technological information, which reflects the original innovation ability and core competencies of a country and a region [4]. Therefore, this study intends to summarize the relevant research status and future development trends in this field and provide reference for relevant researchers' further research work by analyzing the relevant patents of China's water pollution treatment technology from the perspective of patent analysis.

\section{Data Collection and Research Methods}

In this paper, we selected the Soopat Patent Search Database as a patent data source, and built a search strategy with the theme of "water pollution control" by using "key words", "keyword + IPC classification code" and other ways. The search results were further screened to determine the scope of data analysis. The search date is July 22, 2017, and all Chinese patent applications related since 1985 have been retrieved. A total of 11,993 items have been retrieved, in which 62625 are patents of invention, 56199 utility models and 1108 designs. Analysis tools used are Origin and Excel. 


\section{Analysis of Patent Trend in the Field of Water Pollution Control}

Development Trend of Patent Application for Water Pollution Control Technology. Fig. 1 shows our country's patent application development trend of water pollution control technology. From Fig. 1 we can see that China's water pollution control patent applications arouse in 1985, but until 2002 the number of applications was not high, with the annual application of not more than 1000 pieces. From 2003, there was a rapid growth trend. By 2013, the number of applications reached 10,000, and this trend is still accelerating. By 2016, the number of applications reached 17940, which has much to do with the increase of intellectual property protection awareness and the increase of water pollution protection strength.

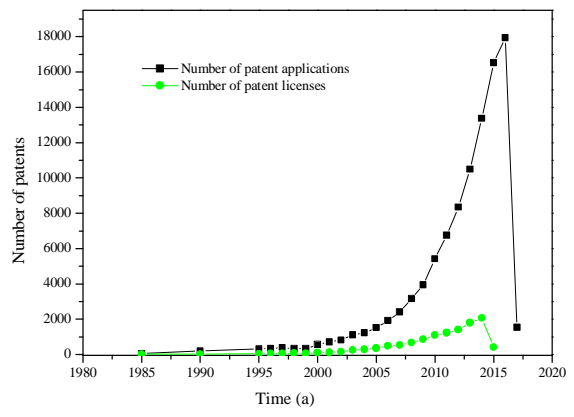

Fig. 1 Patent application and authorization development trend chart about water pollution control technology

The invention patent authorization amount of domestic water pollution control technology upwardly increases. Due to the 18-month period of lag between the patent application filing date and the public day, the invention patent authorization statistics is by the end of 2015, as shown in Fig. 1. It can be seen from Fig. 1, the number of water pollution control patent authorization amount is basically on the rise, the total amount authorized from 46 in 1996 increased to 2068 in 2014. The amount of authorization in 2015 decreased significantly, only 417, partly associated with the research turning of environmental governance key project in the end of Twelfth Five - Year Plan

Applicants and Cooperation Analysis of Water Pollution Control Technology. The domestic water pollution control technology patent applicants are more dispersed, and the top ten applicants according to the number of applications are shown in table 1. As can be seen from Table 1, only two enterprises among the top ten applicants, the remaining eight are colleges and universities, which is attributable to the fact that colleges and universities are important gathering place for innovative talents and research and development institutions. Among the top ten applicants, the largest number of patent applications does not come from colleges and universities, but from China Petroleum and Chemical Corporation (CPCC), up to 878. The number of patented invention patents is also China Petroleum and Chemical Co., Ltd (CNPC). Which reaches up to 251, accounting for the total number of patents granted $1.78 \%$. The total number of patent applications, the number of invention patent applications and the authorization amount of invention patents of ten applicants are calculated as 5262, 3131 and 1539 respectively. It is clear that the total authorization number of invention patents is less than $50 \%$ of the total number of invention patent applications, and the former number is only $10.92 \%$ of the total number of patent authorization. There exists a certain gap compared with developed countries in Europe and America in this field, which indicates that domestic technology innovation ability in this area needs to be further improved.

Scientific and technological innovation ability can be subdivided into patent output ability, patent cooperation ability and patent conversion ability, and patent cooperation ability is an important embodiment of national and regional science and technology innovation ability [5,6]. Table 2 shows the applicants' patent cooperation statistics. From Table 2 we can see that, in this field, the number of cooperation between enterprises and enterprises is zero, the number of patent cooperation 
between enterprises and universities is 5, the number of cooperation between universities and universities is 10 , and the patent cooperation number of different kinds of applicants are all relatively low. From the perspective of patent cooperation ability, China's scientific and technological innovation ability needs to be further improved, and should strengthen the patent cooperation between applicants, especially to strengthen the patent cooperation between universities which have strong research and development ability but lack of self-transformation ability and enterprises with strong conversion ability, to improve the domestic patent conversion rate and the actual utilization rate.

Table 1 Top 10 Patent Applicants Analysis Form of Water Pollution prevention Technology

\begin{tabular}{ccccc}
\hline Applicants & Total & $\begin{array}{c}\text { Pieces of } \\
\text { invention } \\
\text { patent }\end{array}$ & $\begin{array}{c}\text { Authorization } \\
\text { pieces of invention } \\
\text { patent }\end{array}$ & $\begin{array}{c}\text { Authorization } \\
\text { percentage of } \\
\text { invention patent }\end{array}$ \\
\hline $\begin{array}{c}\text { CPCC } \\
\text { Beijing University of } \\
\text { Technology (BJUT) } \\
\text { Harbin Institute of } \\
\text { Technology (HIT) } \\
\text { Tongji University }\end{array}$ & 878 & 507 & 251 & 1.78 \\
$\begin{array}{c}\text { (TJU) } \\
\text { Tsinghua University } \\
\text { (THU) }\end{array}$ & 559 & 491 & 251 & 1.78 \\
$\begin{array}{c}\text { Changzhou } \\
\text { University (CZU) } \\
\text { CNPC }\end{array}$ & 411 & 350 & 242 & 1.72 \\
$\begin{array}{c}\text { Zhejiang University } \\
\text { (ZJU) }\end{array}$ & 396 & 175 & 163 & 1.16 \\
$\begin{array}{c}\text { Nanjing University } \\
\text { (NJU) }\end{array}$ & 363 & 2363 & 147 & 0.54 \\
$\begin{array}{c}\text { Chongqing } \\
\text { University (CQU) }\end{array}$ & 336 & 166 & 100 & 0.71 \\
$\sum$ & 5262 & 3131 & 96 & 0.68 \\
\hline
\end{tabular}

Table 2 Applicants' patent cooperation statistics

\begin{tabular}{ccccccccc}
\hline & CPCC & HIT & TJU & THU & CZU & ZJU & CQU & SDU \\
\hline CPCC & 878 & & & & & & & 2 \\
BJUT & & 825 & 2 & & 2 & & & \\
HIT & & 2 & 707 & & & & & \\
TJU & & & & 559 & & & 2 & \\
THU & 2 & & & 422 & 3 & & \\
\hline
\end{tabular}

Classification Analysis and Technology Development Comparative Analysis in the field of Water Pollution Control. Fig. 2 shows the analysis of field related to water pollution prevention. From Fig. 2, we can see that patent applications are distributed in eight sections of C, B, E, F, A, G, $\mathrm{D}$ and $\mathrm{H}$, in which the top five of application amount come from: section of chemical metallurgy (C), a total of 68619, accounting for 59.69\%, more than half of the total applications of all sections; operation transport (B), a total of 20201, accounting for $17.57 \%$; fixed buildings (E), 7198 items, accounting for $6.26 \%$; mechanical engineering, lighting, heating, weapons, blasting (F), a total of 6269 , accounting for $5.45 \%$; agriculture (A), a total of 4959 , accounting for $4.31 \%$.Three sections 
of Physics (G), textile, paper (D) and electricity (H) respectively accounts for $4.12 \%, 1.48 \%, 1.10 \%$. The above data show that domestic water pollution control patents mainly concentrate on the section of chemical metallurgy and section of operation transport, which is determined by industry characteristics of chemical metallurgy and operation transport.

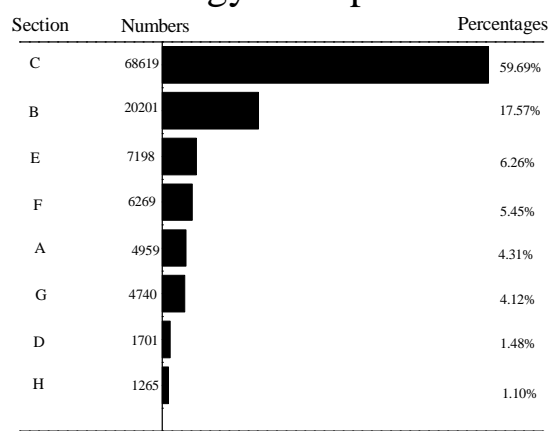

Fig. 2 Distribution picture related to water pollution control field

\begin{tabular}{|c|c|c|}
\hline Class & Numbers & Percentages \\
\hline $\mathrm{C} 02$ & 62762 & $51.10 \%$ \\
\hline B01 & 14693 & $11.96 \%$ \\
\hline E03 & 5277 & $4.30 \%$ \\
\hline G01 & 2840 & $2.31 \%$ \\
\hline $\mathrm{C} 12$ & 2027 & $1.65 \%$ \\
\hline A01 & 1941 & $1.58 \%$ \\
\hline $\mathrm{C} 01$ & 1575 & $1.28 \%$ \\
\hline G05 & 1375 & $1.12 \%$ \\
\hline $\mathrm{C} 10$ & 1289 & $1.05 \%$ \\
\hline A47 & 1265 & $1.03 \%$ \\
\hline $\mathrm{F} 24$ & 1228 & $1.00 \%$ \\
\hline B09 & 1127 & $0.92 \%$ \\
\hline F04 & 1116 & $0.91 \%$ \\
\hline D06 & 1116 & $0.91 \%$ \\
\hline B08 & 1091 & $0.89 \%$ \\
\hline
\end{tabular}

Fig. 3 Top 15 categories of IPC classifications related to water pollution control

Analysis of Technology Layout Based on IPC Classification. Fig. 3 shows the top 15 categories of IPC classifications related to water pollution control. It can be seen from Fig. 3 that the patents involved are mainly distributed in "water, waste water, sewage or sludge treatment" and "general physical or chemical methods or devices", corresponding IPC patent categories are "C02" and "B01". The number of patent applications was 62762 and 14693 respectively, each accounting for $51.10 \%$ and $11.96 \%$ of the total amount of patent applications. There are some directions mainly distributed in the "water supply; drainage", "measurement; test", "biochemistry; beer; spirits wine; fruit juice wine; vinegar; microbiology; enzyme; mutation or genetic engineering", "agriculture; forestry; animal husbandry; hunting; trapping; fishing "," inorganic chemistry "," control regulation "," oil, gas and coal industry; industrial gases containing carbon monoxide; dyes, lubricants; peat", "furniture; household items or equipment; coffee mill; perfume mill; general vacuum cleaner"," heating; stove; ventilation "," solid waste treatment; contaminated soil regeneration "," liquid variable capacity machinery; liquid pump or flexible liquid pump " , "Fabric and others treatment; washing; flexible materials not included by other categories " and "cleaning" and so on. The number of patents in these directions is between 1091 and 5277.

Analysis on Legal Status of Patent for Water Pollution Control. Fig. 4 shows the legal status analysis of water pollution control technology. It can be seen from Fig. 4 that there are 58,239 items $(48.56 \%)$ of the 119932 water pollution control technology patents that have been authorized. There are 14431pieces, accounting for $12.03 \%$, in the substantial examination period; the number of being disclosed is 5252, accounting for $4.38 \%$; the ineffective patent number (including abandonment for avoiding duplication, voluntary abandonment, deemed to be abandonment, withdraw, deemed to be 
withdrawn, annual fee unpaid, expiration, termination, invalidation declaration) is 43010, accounting for $35.86 \%$. Taking into account the specific review process of the invention patent, these patents in disclosure and under substantial examination should be invention patents, accounting for $16.41 \%$ of the patents in this area, less than $20 \%$, indicating that in recent years the domestic patent applications in this area has been reduced. In addition, it can be found that the number of patents owned by patent holders in the relevant domestic areas is high, but a considerable part is in invalid state. This phenomenon reflects the number of patents in the relevant areas of our country is large, but the patent market value and practicality is low, and innovative technology content is low. Patent applications process in the field is easily to be denied by the existing technology, and this also reflects the protection insufficiency of domestic application of patent. And this indicates that there is a certain gap in the aspect of patent applications protection degree compared to the foreign patent holders.

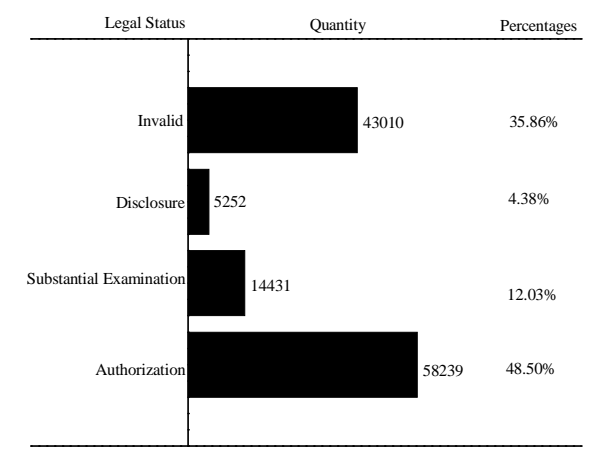

Fig. 4 Analysis picture on legal status of patent for water pollution prevention

\section{Conclusion}

Through the analysis of patent data in the field of domestic water pollution control, the following conclusions can be drawn: the number of patent applications in the field of water pollution control in China is high, and the proportion of invention patents with high technological content is also relatively high; applicants are relatively scattered, less cooperation among applicants, reducing the domestic innovation ability in this area; the fields related to water pollution control are distributed in eight sections, the applications amount of chemical metallurgical section accounts for $59.69 \%$ of the total applications, followed by the section of operation transport, accounting for $17.57 \%$, these two sections are also the fastest growing sections of patent applications. The analysis of the technical layout based on IPC classification shows that the patents involved in water pollution control are mainly distributed in two categories of "water, wastewater, sewage or sludge treatment" and "general physical Or chemical methods or devices ", each accounting for $51.10 \%$ and $11.96 \%$ respectively in the total amount of patent applications; patent legal status analysis shows that relative amount of our large number of patents in this area is invalid, we should strengthen the innovation and technical protection in this field.

\section{Acknowledgements}

This work was supported by Natural Science Foundation of Daqing Normal University (12ZR07).

\section{References}

[1] S. S. James, W. D. James: submitted to American Journal of Agricultural Economics (1986). 
[2] C. G. Mahesh: submitted to International Journal of Operations \& Production Management (1995).

[3] K. Liddell, S. Hogarth, D. Melzer: submitted to Intellectual Property Quarterly (2008).

[4] Y. Guo, B. Wang: submitted to Journal of Management \& Sustainability (2012).

[5] J. Guan, N. Ma: submitted to Technovation (2003).

[6] S. Gopalakrishnan: submitted to Omega (1997). 